\title{
Experimental Study on the Effect of Freezing and Thawing on the Shear Strength of the Frozen Soil in Qinghai-Tibet Railway Embankment
}

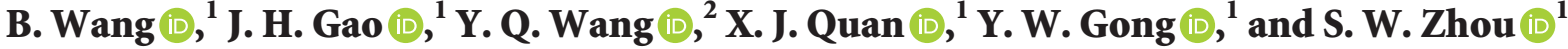 \\ ${ }^{1}$ Key Laboratory of Transportation Tunnel Engineering, Ministry of Education, Southwest Jiaotong University, \\ Chengdu 610031, China \\ ${ }^{2}$ Key Laboratory of Highway Bridges and Tunnels of Shaanxi Province, Chang'an University, Xi'an 710054, China
}

Correspondence should be addressed to Y. Q. Wang; ys08@gl.chd.edu.cn and X. J. Quan; quanxiaojuan@swjtu.edu.cn

Received 21 October 2021; Accepted 2 December 2021; Published 5 January 2022

Academic Editor: Chunchi Ma

Copyright $\odot 2022$ B. Wang et al. This is an open access article distributed under the Creative Commons Attribution License, which permits unrestricted use, distribution, and reproduction in any medium, provided the original work is properly cited.

The direct shear tests of different dry density and moisture content samples at different temperatures of the frozen soil in the Qinghai-Tibet Railway embankment between Tanggula South and Anduo section were carried out to analyze the influence rules of each experimental factor on the mechanical properties of frozen soil during the freeze-thaw process. The results show the following. (1) When the frozen soil temperature is below $0^{\circ} \mathrm{C}$ and continues to drop during the freezing and thawing process, each sample shows the law of a significant increase in cohesion and a slight decrease in the internal friction angle. In the meantime, the cohesion obtained during the thawing process of the sample at the same temperature point is higher than that obtained during the freezing process. In contrast, the internal friction angles exhibit an opposite law, where the internal friction angle during the melting process is lower than the internal friction angle during the freezing process. After freezing-thawing action, it deserves to be mentioned that the cohesion increases slightly while the internal friction angles present a slight decrease trend compared to the initial state. (2) With the decrease in temperature and the gradual increase in cohesion, the temperature curve can be divided into a fast-growing section from 0 to $-2^{\circ} \mathrm{C}$, a slow-growing section from -2 to $-8^{\circ} \mathrm{C}$, and a second fast-growing section from -8 to $-10^{\circ} \mathrm{C}$ owing to the combined effect of the pressure-thawing action and ice-water phase change. In addition, the rate of decrease in the internal friction angle also shows a similar pattern. (3) The cohesion and the internal friction angle of samples both tend to increase first and then decrease with the rise of the initial moisture content, and the critical initial moisture content is near the optimal moisture content of $15 \%$. (4) Both the cohesion and the internal friction angle of the samples increase with dry density growth. The growth rate of cohesion will gradually increase as the temperature decreases. Moreover, the growth rate of cohesion of low dry density samples is more susceptible to temperature, while the internal friction angle growth rate is not affected by temperature.

\section{Introduction}

Permafrost is generally defined as a negative temperature or ice-bearing zero-temperature rock and soil that has been in a frozen state for more than two years [1]. The combined effects of human activities and global warming have resulted in significant degradation of permafrost areas and a continuous increase in average ground temperature worldwide [2]. From 1964 to the present, permafrost has degraded at least $25 \mathrm{~km}$ northward in southern Yukon, Canada, and at the southern boundary of the Alaska North Highway corridor [3]. Since the 1980s, permafrost degradation has accelerated its way in Scandinavia, northern Sweden, with nine permafrost layers decreasing in thickness and three permafrost areas disappearing completely $[4,5]$. It is notable that, in recent years, the growth rate of the permafrost active layer in the border areas of Russia and Mongolia is $3-5 \mathrm{~cm}$ per year, and in some regions, it exceeds $5 \mathrm{~cm}$ per year with a continuously expanding range. Similarly, the Qinghai-Tibet Plateau, the "world's third pole" in China, has also seen a 30\% decrease in 
permafrost areas [6]. In the process of permafrost degradation to seasonally frozen soil, undesirable phenomena such as thawing mudflow and thermal thawing subsidence emerge to infinity, posing a significant threat to the stability and safety of structures like railways, highways, and pipelines [7-12], where the yearly freeze-thaw cycle is critical for the deterioration of permafrost foundation engineering properties. The Qinghai-Tibet Railway currently has built about $960 \mathrm{~km}$ of lines, located $4000 \mathrm{~m}$ above sea level, with over $500 \mathrm{~km}$ of lines passing through permafrost regions [13]. Inevitably, the risk of potential safety hazards associated with the abovementioned frozen soil degradation increases year by year $[14,15]$. Therefore, it is particularly important to ascertain the deterioration law of mechanical properties of railway subgrade frozen soil under freeze-thaw action.

Concerning the influence of freezing and thawing on the mechanical properties of frozen soil, the current research focuses mainly on the characteristics of strength, module, and stress-deformation curve, among others. In the study of the effect of freezing and thawing on the strength of soil, many scholars have carried out research on the shear strength change pattern under multiple freezing and thawing cycles for different soil samples. In summary, a large number of research results indicate that the shear strength of different types or even the same type of soil samples may have large differences in the changes in shear strength under the effects of freezing and thawing [16-24]. Generally, the shear strength is influenced by the particle skeleton, mineral composition, and structural arrangement of frozen soil; in addition, the temperature, moisture content, external pressure, and load duration of frozen soil will also affect its shear strength [25]. At the same time, the main direction of current research is to focus on the influence of freezing and thawing cycles on the strength of frozen soil, while there are few studies on the evolution of frozen soil strength during the freezing and thawing process. However, the mechanical degradation of engineering frozen soil is a long-term and continuous process. In order to have a clearer understanding of the evolution of the mechanical properties of the QinghaiTibet Railway subgrade permafrost under the effects of freezing and thawing, direct shear tests were carried out on frozen plateau powder clay collected from the embankment of the subgrade of the Tanggula South and Anduo section of Qinghai-Tibet Railway at different initial moisture contents and dry densities under various temperatures during the freeze-thaw process. The results can further supplement the research field of the impact of freezing-thawing on the mechanical properties of permafrost on the Qinghai-Tibet railway subgrade and provide a theoretical reference basis for the study of the perennial deformation of the roadbed of Qinghai-Tibet Railway and the safe operation and maintenance of Qinghai-Tibet Railway in the future.

\section{Sample Preparation and Experimental Method}

2.1. Sample Preparation. The test in-situ soil samples were taken from the subgrade of the Qinghai-Tibet Railway between Tanggula South and Anduo section, inspected and processed on site after sampling, sealed and labeled for packaging, and then transported back to the laboratory for the following testing.

As shown in Table 1, the basic physical property parameters of the soil samples were obtained through the indoor soil test. Subsequently drying the undisturbed soil samples naturally, milling them to fine particles with a wooden whisk, and then passing them through a $2 \mathrm{~mm}$ sieve allowed insight into the graph of the soil grain gradation curve shown in Figure 1, with the unevenness coefficient $C_{u}=5.73$ and the curvature coefficient $C_{c}=1.25$, which proved it to be unevenly graded soil.

The direct shear tests were conducted using remodeled soil, and the samples were prepared in accordance with the Chinese Standard for Geotechnical Test Methods (GBT 50123-2019): a certain quality of sieved soil was blended and mixed thoroughly according to the experimentally set moisture content to ensure uniform distribution of coarse and fine soil particles. Then the well-mixed samples were sealed in plastic bags and left to stand for 24 hours to make the moisture fully and uniformly penetrate the soil particles. After completing the standing, the required mass of the cylindrical sample with $D=61.8 \mathrm{~mm}$ and $h=20 \mathrm{~mm}$ was weighed according to the test expectations, and the soil sample was compacted in three layers by using compaction equipment (Figure 2), and the surface of the soil sample was entirely scraped with a knife immediately following each compaction to enhance the connection between the layers for the sake of obtaining various dry density samples. After that, the prepared samples were wrapped tightly with preservative film to prevent moisture loss and subsequently put into the low-temperature freezer for freezing, as shown in Figure 3.

2.2. Experimental Method. The experimental method involved three concerning factors: moisture content, dry density, and temperature. The moisture content of the sample was, respectively, set to $12 \%, 15 \%, 18 \%$, and $20 \%$. In the meantime, the dry density was set to $1.6 \mathrm{~g} / \mathrm{cm}^{3}, 1.7 \mathrm{~g} / \mathrm{cm}^{3}$, and $1.8 \mathrm{~g} / \mathrm{cm}^{3}$. On this basis, 12 groups of samples with different moisture content and dry density (each group contained at least eight samples to meet the requirements of the parallel experiment) were prepared and are shown in Table 2. Simultaneously, the shear temperature points during freeze-thaw were sequentially set to $2.0^{\circ} \mathrm{C}, 0^{\circ} \mathrm{C}$, $-2.0^{\circ} \mathrm{C},-5.0^{\circ} \mathrm{C},-8.0^{\circ} \mathrm{C},-10.0^{\circ} \mathrm{C},-8.0^{\circ} \mathrm{C},-5.0^{\circ} \mathrm{C},-2.0^{\circ} \mathrm{C}, 0^{\circ} \mathrm{C}$, and $2.0^{\circ} \mathrm{C}$, which indicated that the direct shear test was carried out at the same temperature point on the freezing and thawing path.

To ensure the accuracy of the soil sample temperature during shearing and to prevent heat migration due to excessive temperature discrepancy during the tests from affecting the experimental results, the samples and the direct shear test boxes were stored separately in a low-temperature freezer with constant computerized temperature control in the range of $-30 \sim 10^{\circ} \mathrm{C}$. The direct shear tests were carried out in the programmable high- and low-temperature ambient temperature test chamber that can be configured at a 
TABLE 1: Basic physical properties parameters of soil samples.

\begin{tabular}{lcccc}
\hline Dry density $\left(\mathrm{g} / \mathrm{cm}^{3}\right)$ & Optimal moisture content $(\%)$ & Liquid limit $(\%)$ & Plastic limit $(\%)$ & Plasticity index $(\%)$ \\
\hline 1.6 & 15 & 27.6 & 12.6 & 15 \\
\hline
\end{tabular}

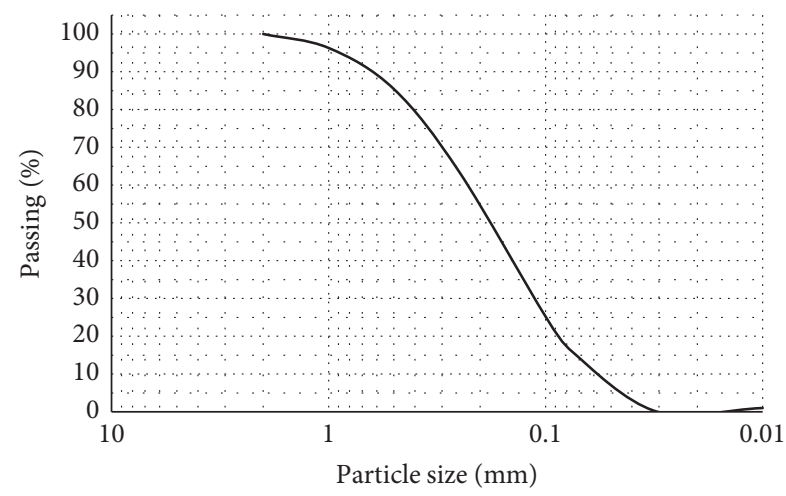

FIGURE 1: Particle gradation curve of soil samples.

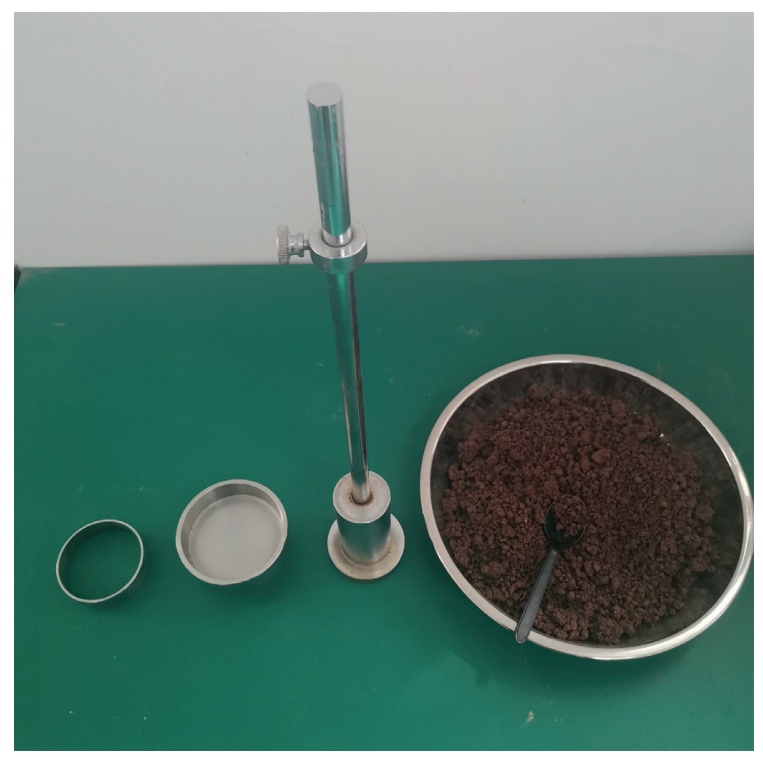

Figure 2: Compacted soil samples.

constant temperature in the range of $-50 \sim 20^{\circ} \mathrm{C}$ (Figures 4 and 5) at the Key Laboratory of High-Speed Railway Engineering, Ministry of Education, Southwest Jiaotong University.

Before the tests, all the samples and the direct shear test boxes were placed in the constant temperature freezer separately with the temperature adjusted to $2^{\circ} \mathrm{C}$ for 24 hours to ensure the uniform initial temperature distribution of the soil samples and reduce the influence of heat migration between the test boxes and samples. And then, the samples were quickly moved to the thermostatic test chamber with the same temperature set in advance to start the first direct shear test. Afterward, the temperature of the thermostatic freezer was adjusted to each shear temperature point in sequence for 8 hours to ensure that the samples reached the specified temperature; then the next

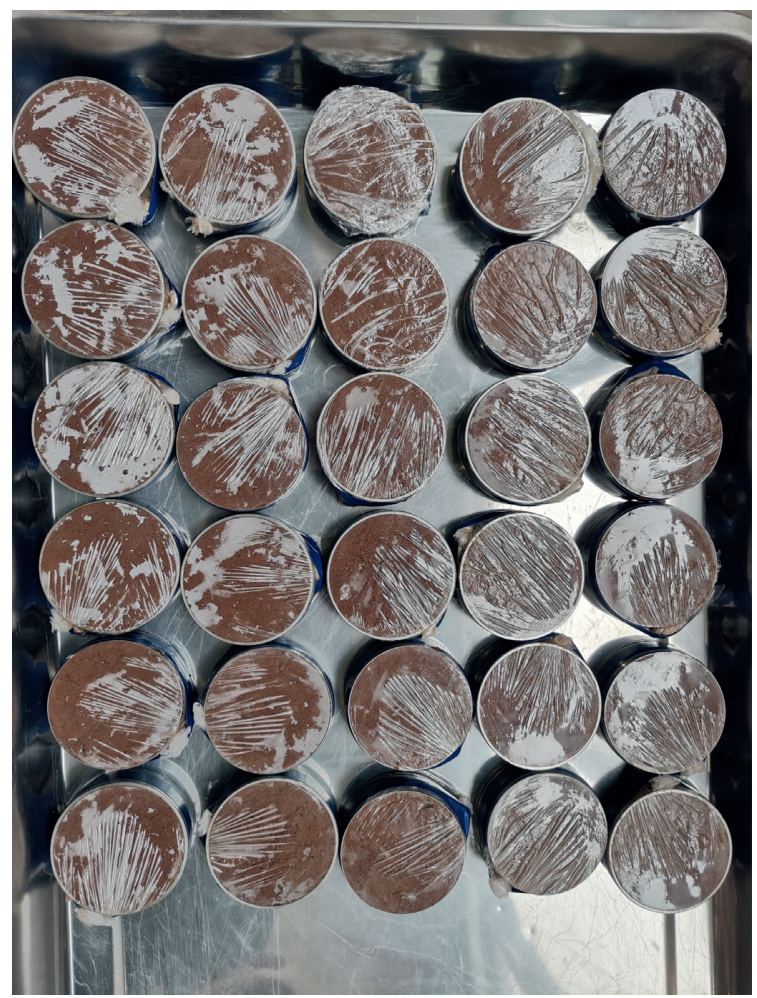

Figure 3: Physical image of the samples.

direct shear test was carried out and repeated until freezethaw was complete.

Since the long loading time of vertical pressure in the direct shear test would cause a certain amount of heat transfer to the samples, the direct fast shear tests were conducted in this test. And because the samples were taken from the shallow layer of the railway subgrade, the vertical pressure setting for the tests was small. Consequently, the test rate was set to $0.8 \mathrm{~mm} / \mathrm{min}$, and the vertical pressure was set to $50,100,150$, and $200 \mathrm{kPa}$, respectively, in order.

\section{Analysis}

\subsection{Variation of Shear Strength and Temperature of Frozen Soil during Freezing-Thawing Process}

3.1.1. Variation of Cohesion with Temperature. Since the variation pattern of cohesion with temperature is similar for each sample group, four groups of FT1, FT2, FT3, and FT4 with the same dry density of $1.6 \mathrm{~g} / \mathrm{cm}^{3}$ as the in-situ soil were selected to plot the results of cohesion with temperature change as shown in Figures 6(a)-6(d). In Figure 6, the blue line represents the freezing process with the direction from left to right, while the red line represents the thawing process with the opposite direction. 
TABLE 2: Samples of direct shear tests.

\begin{tabular}{lccccccc}
\hline No. Dry density $\left(\mathrm{g} / \mathrm{cm}^{3}\right)$ & Moisture content (\%) & No & $\begin{array}{c}\text { Dry density } \\
\left(\mathrm{g} / \mathrm{cm}^{3}\right)\end{array}$ & Moisture content $(\%)$ & No & $\begin{array}{c}\text { Dry density } \\
\left(\mathrm{g} / \mathrm{cm}^{3}\right)\end{array}$ & $\begin{array}{c}\text { Moisture content }(\%) \\
\text { FT1 }\end{array}$ \\
FT2 & 12 & FT5 & & 12 & FT9 & 12 \\
FT3 & 1.6 & 15 & FT6 & 1.7 & 15 & FT10 & 1.8 \\
FT4 & 20 & FT7 & FT8 & & 18 & FT11 & 15 \\
\hline
\end{tabular}

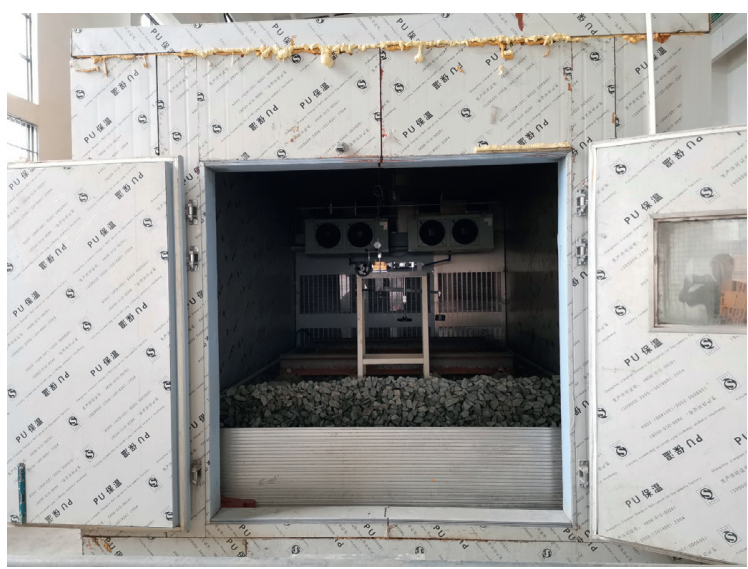

Figure 4: Programmable high- and low-temperature environment temperature test chamber.

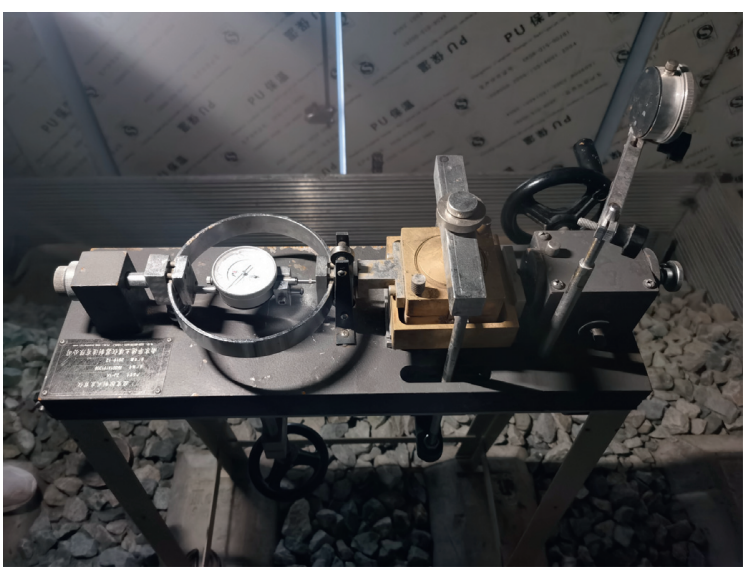

FIgURE 5: Direct shear tester in the chamber.

It can be seen from Figure 6 that the cohesion of each moisture content sample remains unchanged above $0^{\circ} \mathrm{C}$ regardless of being in freezing or thawing stage, indicating that the water in the samples exists in the form of liquid at this time, which basically does not affect cohesion. While the temperature is below $0^{\circ} \mathrm{C}$ and is decreasing continuously, the cohesion commences increasing, which indicates that the rising of ice content is due to the gradual crystallization of water, resulting in the gradual increase of ice cementation. Taking the FT2 group for example, with the same moisture content as the undisturbed soil, the freezing process temperature varying from $0^{\circ} \mathrm{C}$ to $-10^{\circ} \mathrm{C}$, the cohesive force raises from $16.83 \mathrm{kPa}$ to $57.38 \mathrm{kPa}$, with an increase of about $255 \%$, showing that the temperature of frozen soil has a significant effect on its cohesion. While the thawing process temperature varies from $-10^{\circ} \mathrm{C}$ to $0^{\circ} \mathrm{C}$, the cohesive force decreases to $19.23 \mathrm{kPa}$, increasing by $14.3 \%$ compared to the state before freezing. Moreover, the curve of each thawing process is located above that of the freezing process, indicating that the freeze-thawing action increases the cohesion of the sample. And the cohesion obtained from the thawing process of the sample is higher than that of the freezing process at the same shear temperature, which is different from the conclusion that the cohesion of the sample is reduced by the freeze-thawing effect mentioned in some literature [22-27]. The main reason for the difference is that the cohesion of the soil is related to the connection way of the soil. The freeze-thaw action would destroy the original 


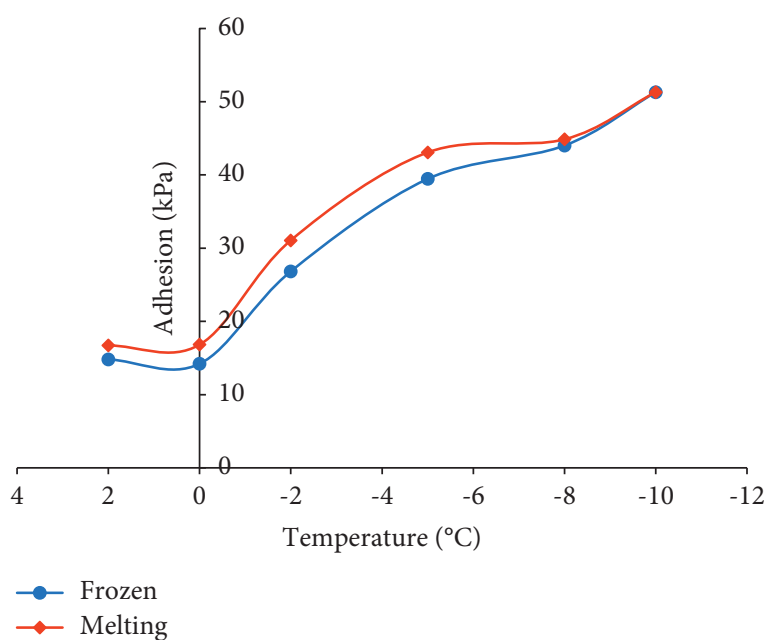

(a)

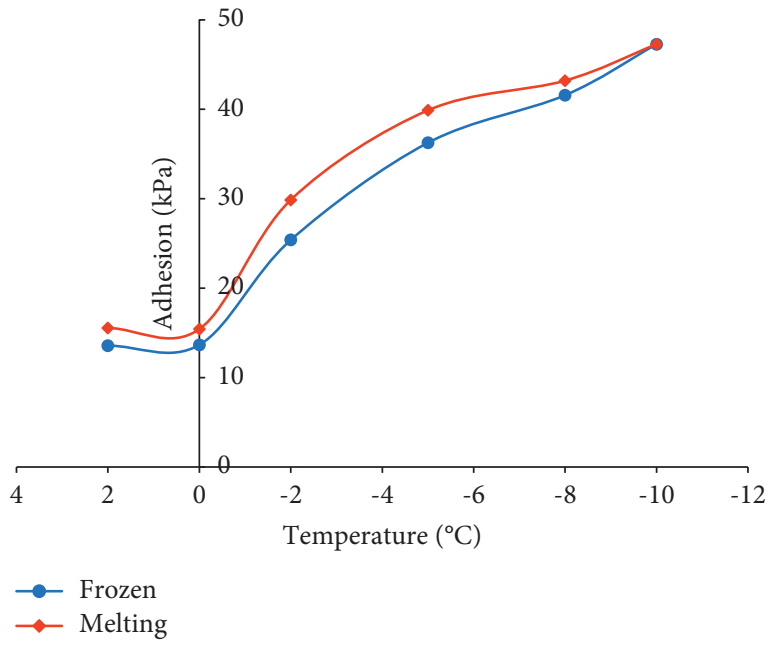

(c)

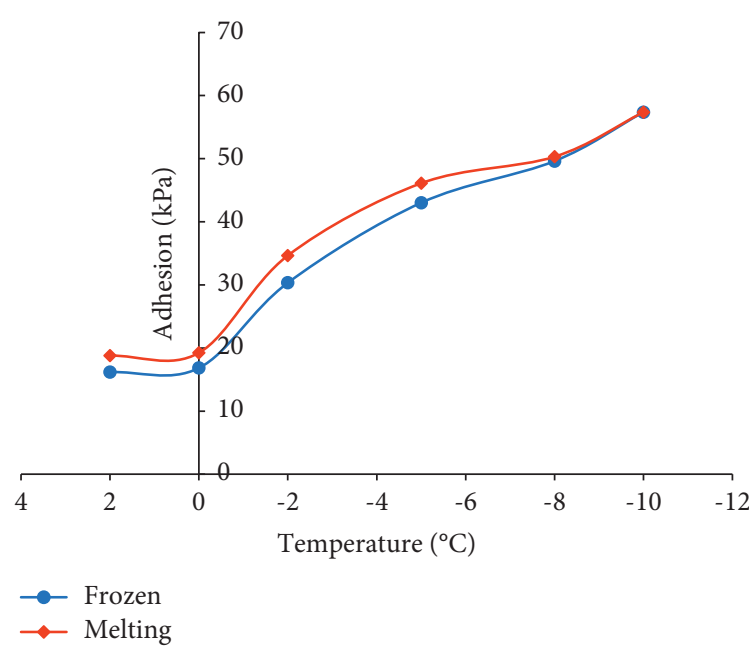

(b)

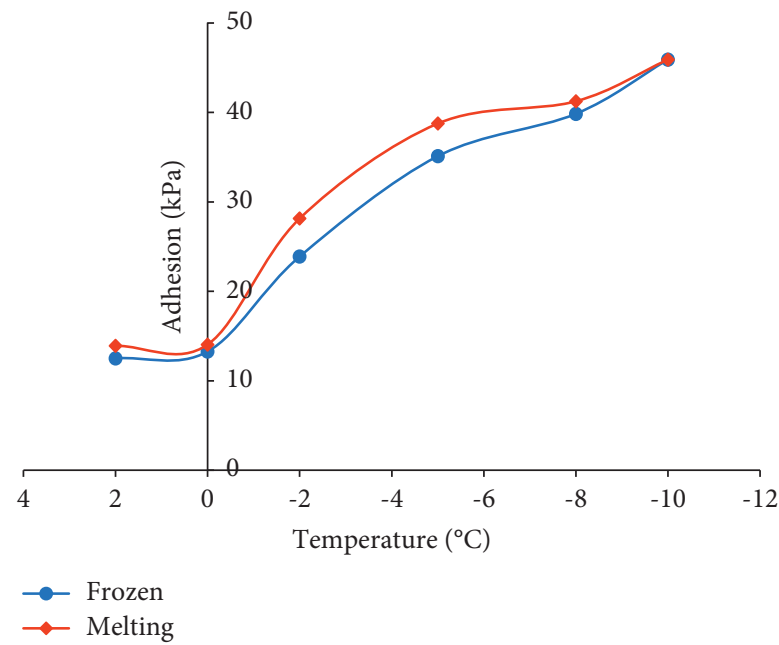

(d)

Figure 6: Variation curve of cohesion $c$-temperature of $1.6 \mathrm{~g} / \mathrm{m}^{3}$ dry density sample groups. (a) FT1. (b) FT2. (c) FT3. (d) FT4.

connection between soil particles and rearrange them by frost-heave and thawing settlement, which may change the cohesion of the sample. However, when the soil particles of the sample are rearranged and the connection way produced is inferior to the original sample, the cohesion is naturally reduced. However, when the connection is superior to the original sample, it performs an opposite property. Obviously, the case of the sample in this paper belongs to the latter.

The experimental results of other sample groups were similar. Based on the value of the cohesive strength at $0^{\circ} \mathrm{C}$ during the freezing process, the cohesion of the remaining sample groups increased by $241 \sim 295 \%$ when frozen at $-10^{\circ} \mathrm{C}$ compared with that before freezing, and the cohesive force of the heating and melting to $0{ }^{\circ} \mathrm{C}$ was also increased by $0.5 \%$ $21.1 \%$ compared with that before freezing.

It is also worth noting that the $0 \sim-10^{\circ} \mathrm{C}$ section of each curve can be roughly divided into three parts according to the change of the slope, where it is firstly steeper in the range of $0 \sim-2^{\circ} \mathrm{C}$, while it gradually tends to slow down in the range of $-2 \sim-8^{\circ} \mathrm{C}$; finally, it presents a second steepening in the range of $-8 \sim-10^{\circ} \mathrm{C}$. During freezing and thawing at test temperatures below $0^{\circ} \mathrm{C}$, two phenomena affect the curve change pattern: the ice-water phase change and the pressurethawing effect. When the sample temperature changes in the range of $0 \sim-2^{\circ} \mathrm{C}$, it is close to the freezing point of water in the soil; hence the ice-water phase changes drastically. Although the pressure-thawing effect exists, it is dominated by ice-water phase transformation. With the decrease in temperature, a large amount of free water in the soil will be rapidly transformed into ice crystals, rapidly exerting strength and producing a cementing effect on the soil particles, resulting in a dramatic increase in the cohesion between soil particles. When the temperature is in the range of -2 to $-8^{\circ} \mathrm{C}$, most of the water has frozen into ice, and as the temperature continues to drop, only a small amount of water remains to continue the phase change. In the meantime, the pressure-thawing effect also inhibits the rate of transformation of the remaining water into ice, which leads to a slowing down of the curve slope. However, the 


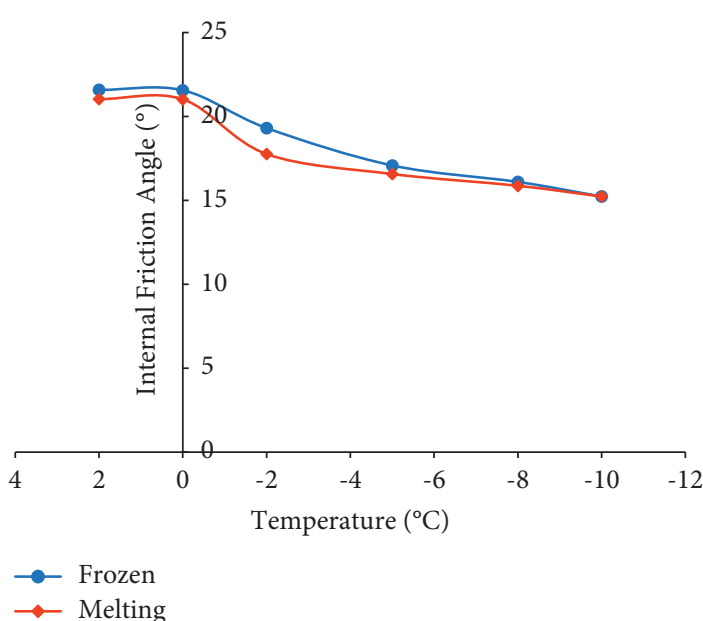

(a)

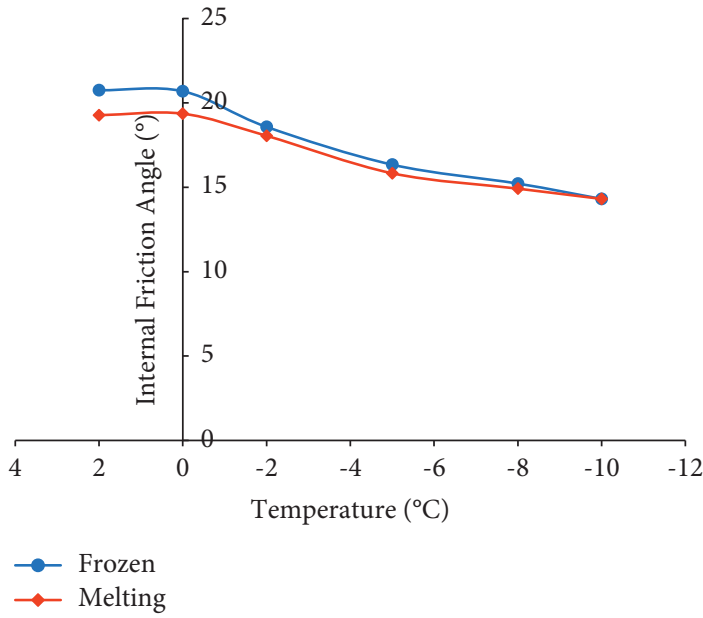

(c)

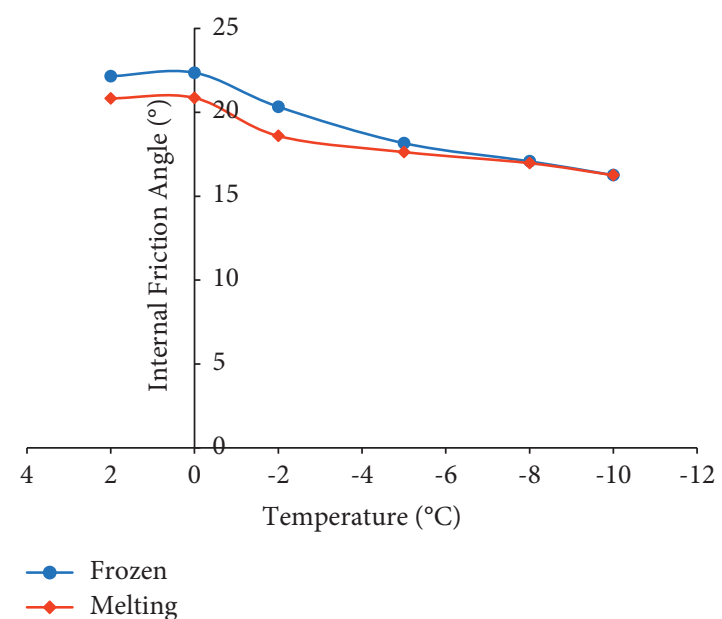

(b)

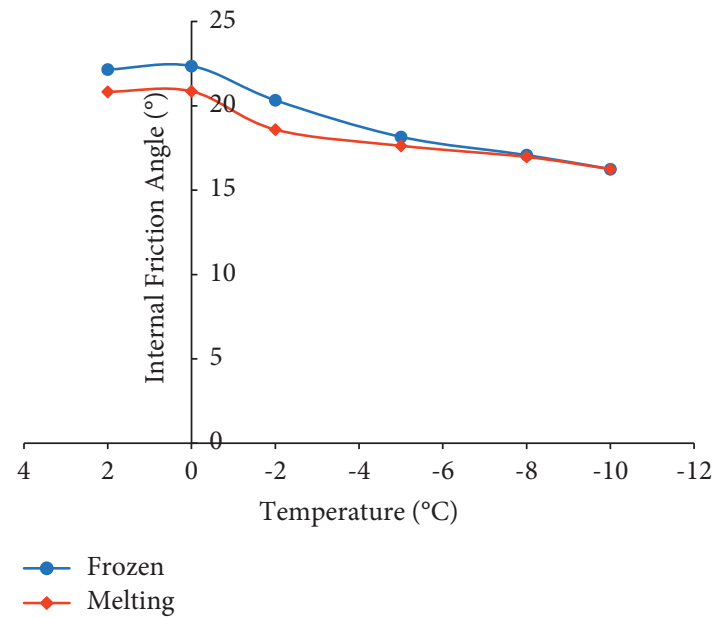

(d)

FiguRE 7: Internal friction angle $\varphi$-temperature curve of $1.6 \mathrm{~g} / \mathrm{m}^{3}$ dry density sample groups. (a) FT1. (b) FT2. (c) FT3. (d) FT4.

pressure-thawing effect of frozen soil will gradually disappear with the decrease of temperature [21]. Therefore, when the temperature is in the range of $-8 \sim-10^{\circ} \mathrm{C}$, the remaining water phase change speed increases due to the weakening of the pressure-thaw effect, resulting in a second remarkable increase in cohesion.

3.1.2. Variation of the Internal Friction Angle with Temperatures. For the same reason as above, four groups of FT1, FT2, FT3, and FT4 samples with the same dry density as the undisturbed soil of $1.6 \mathrm{~g} / \mathrm{cm}^{3}$ with different moisture contents were selected to draw the curve of internal friction angle $\varphi$ with various temperatures, and only the quantitative analysis of FT2 sample group was carried out, as shown in Figure 7.

It can be seen from Figure 7 that the internal friction angle is not affected by the temperature at $2 \sim 0^{\circ} \mathrm{C}$. As the temperature is lower than $0^{\circ} \mathrm{C}$ and continues to decrease, the internal friction angle will decrease accordingly during the freezing and thawing process. This is because, in the process of ice-water phase transformation, the conversion of water to ice will cause volume expansion, crowding, and expanding the soil pores, which results in a lower degree of soil particle occlusion. And the strength of ice crystals is much lower than that of soil particles, which will further lead to a decrease in the internal friction angle of the samples. Meanwhile, the reduction rate within the $0 \sim-2^{\circ} \mathrm{C}$ section is significantly faster than that of the $-2 \sim-8^{\circ} \mathrm{C}$ section, and the reduction rate within the $-8 \sim 10^{\circ} \mathrm{C}$ is also slightly faster than that of the $-2 \sim-8^{\circ} \mathrm{C}$ section, and the reason is similar to the cohesion influenced by the ice-water phase change and pressure-thawing action. While, in terms of values, taking FT2 for example, the freezing process temperature decreases from $0^{\circ} \mathrm{C}$ to $-10^{\circ} \mathrm{C}$, the internal friction angle drops from $22.36^{\circ}$ to $16.25^{\circ}$, decreasing by about $26.6 \%$. With thawing process temperature varying from $-10^{\circ} \mathrm{C}$ to $0^{\circ} \mathrm{C}$, the internal friction angle rises from $16.25^{\circ}$ to $20.86^{\circ}$, reducing by about $6.7 \%$ compared with the state before freezing. And, the internal friction angle obtained during the thawing process at the same shear temperature point is lower than that of the freezing process, which is related to the expansion and deformation of the pores during the freezing process, leading to the decrease of the occlusion between soil particles. 


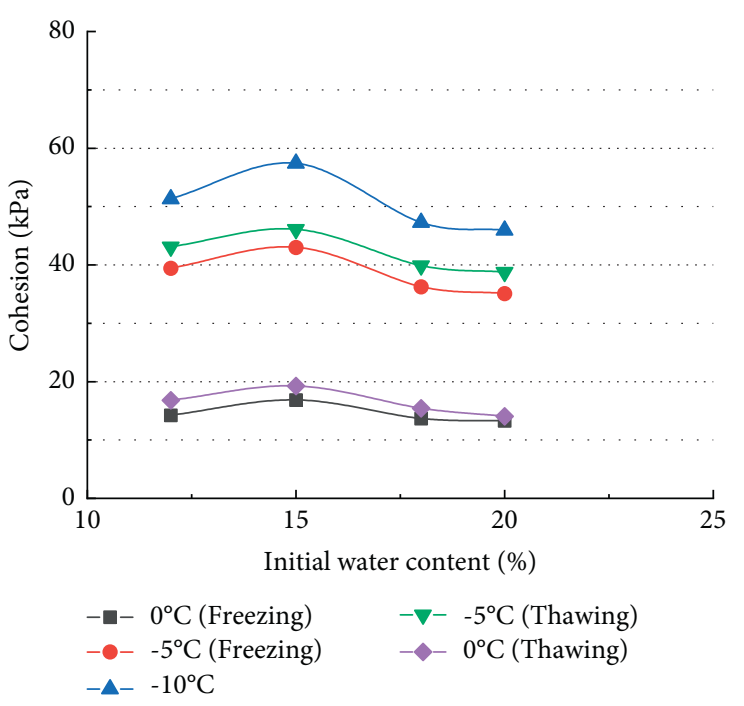

(a)

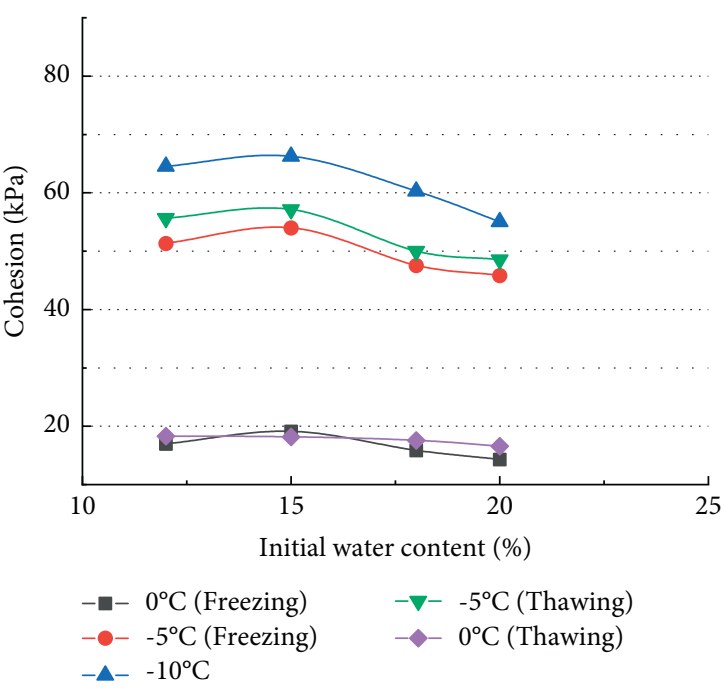

(b)

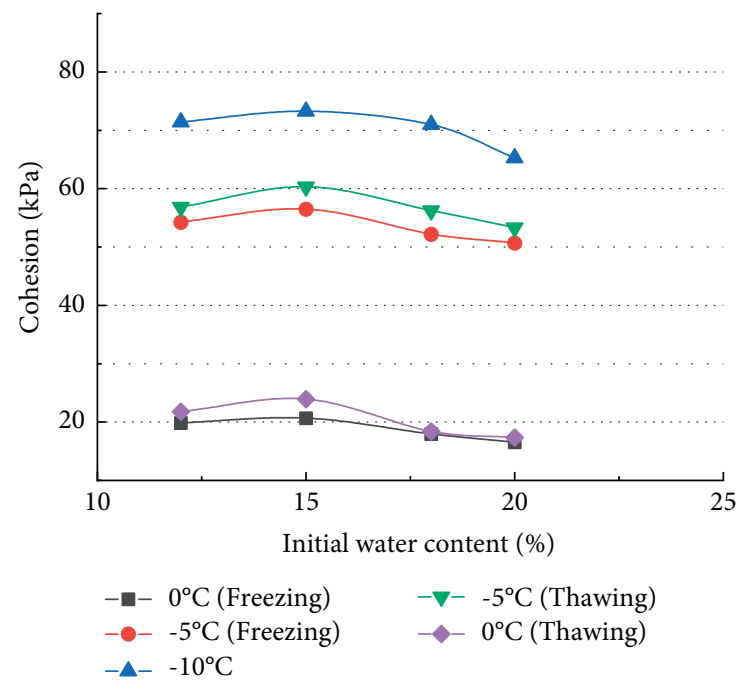

(c)

FIgURE 8: Relationship curve between cohesion $c$ of the sample group and initial moisture content under freeze-thaw action. (a) Dry density $1.6 \mathrm{~g} / \mathrm{cm}^{3}$. (b) Dry density $1.7 \mathrm{~g} / \mathrm{cm}^{3}$. (c) Dry density $1.8 \mathrm{~g} / \mathrm{cm}^{3}$.

The experimental results of other sample groups are similar. Based on the value of internal friction angle before freezing at $0^{\circ} \mathrm{C}$, the internal friction angle of other sample groups decreased by $23.5 \% \sim 34.5 \%$ when frozen at $-10^{\circ} \mathrm{C}$, and the internal friction angle of other sample groups decreased by $2.1 \% \sim 8.4 \%$ when thawed to $0^{\circ} \mathrm{C}$. In general, temperature has a smaller effect on the angle of internal friction compared to cohesion.

\subsection{Effect of Initial Moisture Content on the Shear Strength of} Frozen Soil during Freezing and Thawing Process. In order to explore the influence of the initial moisture content of the sample on the shear strength of the frozen soil during the freezing and thawing process, the typical temperatures $\left(0^{\circ} \mathrm{C},-5^{\circ} \mathrm{C},-10^{\circ} \mathrm{C}\right)$ were selected in each group of the same dry density. The relationship was plotted between cohesion and internal friction angle $\varphi$ with initial moisture content during the freeze-thaw process, as shown in Figures 8 and 9 .

Figures 8 and 9 reveal that there are some similar rules for the curves of cohesion and internal friction angle. Whether it is during the freezing or thawing process, the cohesion and internal friction angle both increase first and then decrease with the rising of initial moisture content, and the maximum values of both parameters are obtained at the initial moisture content of $15 \%$, which is also the optimum moisture content. It indicates that a certain critical moisture content exists at or near the optimal point at each test temperature, which gives the sample the maximum cohesion or internal friction angle. And the optimal moisture content in this work is defined as the moisture content corresponding to the maximum compaction state of the soil under a certain number of ramming times; that is, the soil particles are easily compressed and connected closely under this moisture content, and the sample is accessible to obtain 

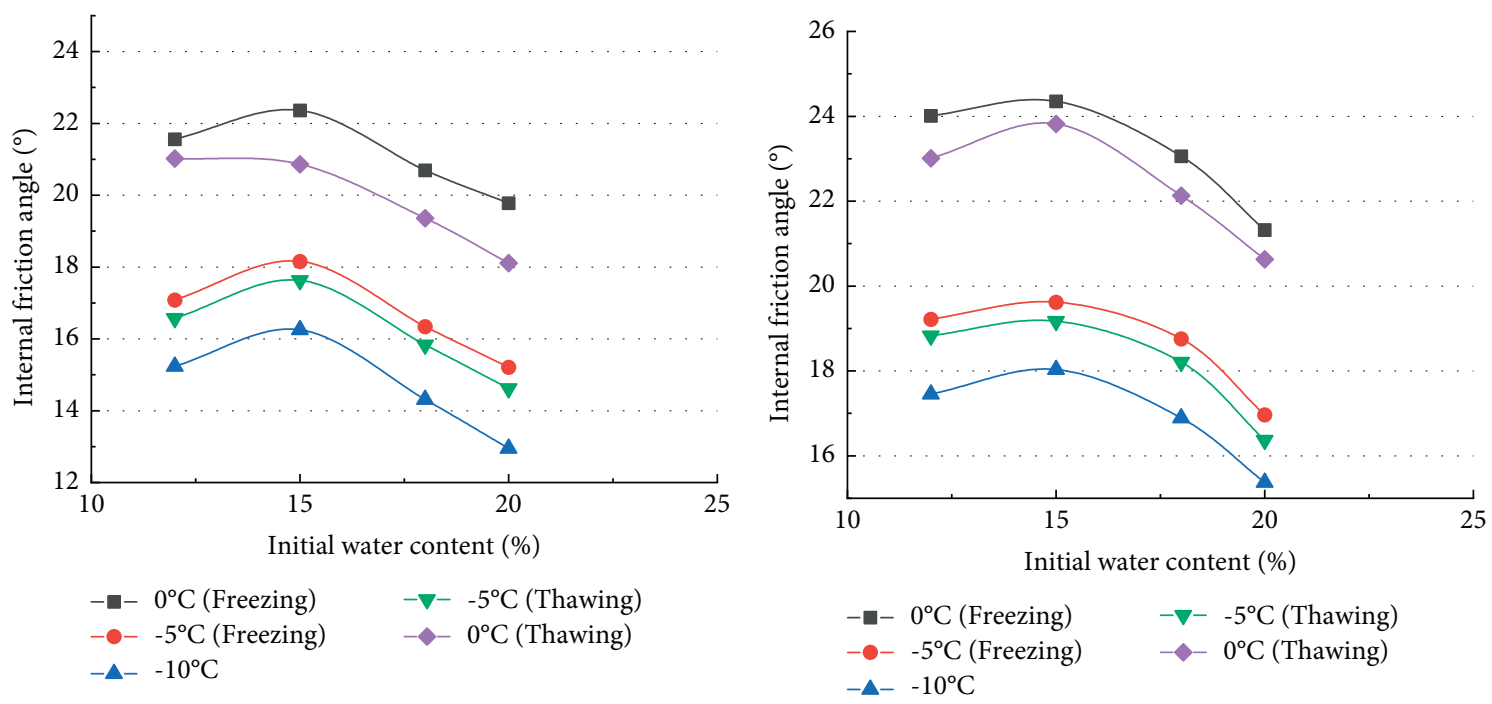

(a)

(b)

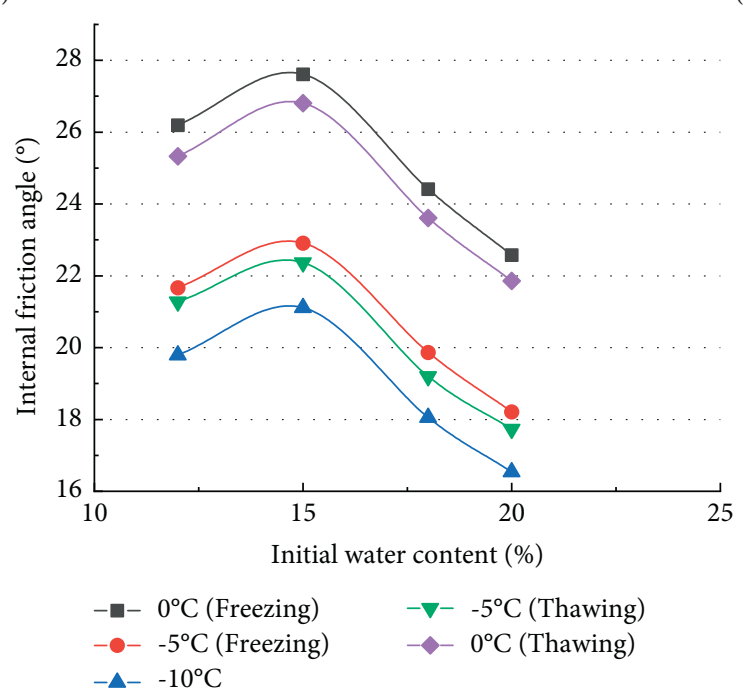

(c)

FIGURE 9: Relationship curve between internal friction angle $\varphi$ of the sample group and initial moisture content under freeze-thaw action. (a) Dry density $1.6 \mathrm{~g} / \mathrm{cm}^{3}$. (b) Dry density $1.7 \mathrm{~g} / \mathrm{cm}^{3}$. (c) Dry density $1.8 \mathrm{~g} / \mathrm{cm}^{3}$.

the maximum shear strength parameters at this time. However, as the temperature decreased, the water crystallization inside the soil sample frosted and heaved, and the water content may change. The reason for this rule is analyzed as follows: when the moisture content is lower than the critical moisture content, the phase change occurs with the decrease of temperature, and the internal pores of the soil are gradually filled with ice crystals, which reinforces the soil strength. However, as the moisture content continues to increase, the ice crystals gradually fill up and further frostheave the large pores, which increases the gap between soil particles and weakens the intermolecular force and occlusion of soil particles, thereby weakening the soil strength.

3.3. Effect of Dry Density on the Shear Strength of Frozen Soil during Freezing and Thawing Process. In order to explore the influence of sample dry density on the shear strength of frozen soil during the freeze-thaw process, the typical temperatures $\left(0^{\circ} \mathrm{C},-5^{\circ} \mathrm{C},-10^{\circ} \mathrm{C}\right)$ were selected in each sample group with the same initial moisture content. The relationship curves of cohesion $c$ and internal friction angle $\varphi$ with dry density during the process were drawn correspondingly as shown in Figures 10 and 11.

It can be seen from Figures 10 and 11 that the sample's cohesive force and internal friction angle increase with the dry density growth at each stage of freezing and thawing, but the growth curves of the cohesive force and internal friction angle are different.

For the cohesion, the curve characteristics of each water content curve group are similar. Taking Figure 10(a) as an example, when the temperature is $0^{\circ} \mathrm{C}$, the cohesion increases linearly and the growth rate is relatively slow. As the temperature drops to $-5^{\circ} \mathrm{C}$, the linear characteristics of the curve disappear, showing that the front-end growth rate is greater than the back-end, and the front-end growth rate is 


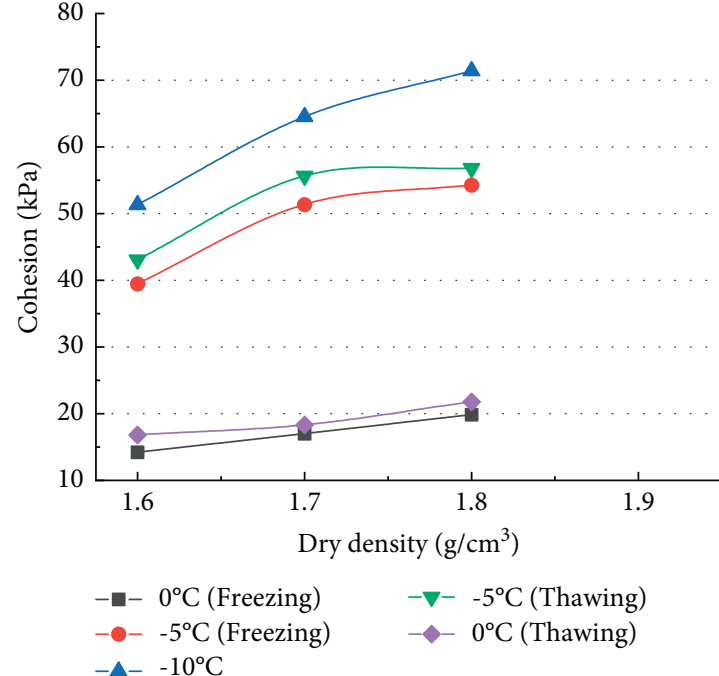

(a)

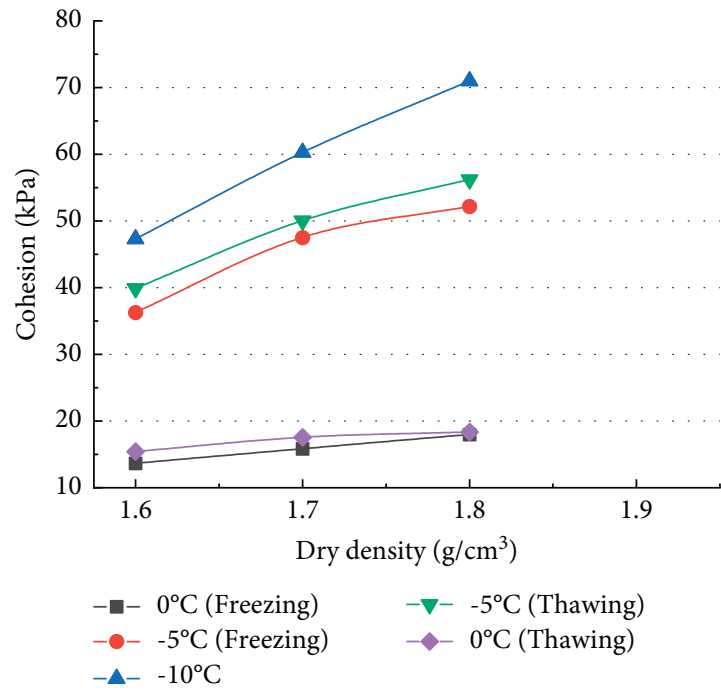

(c)

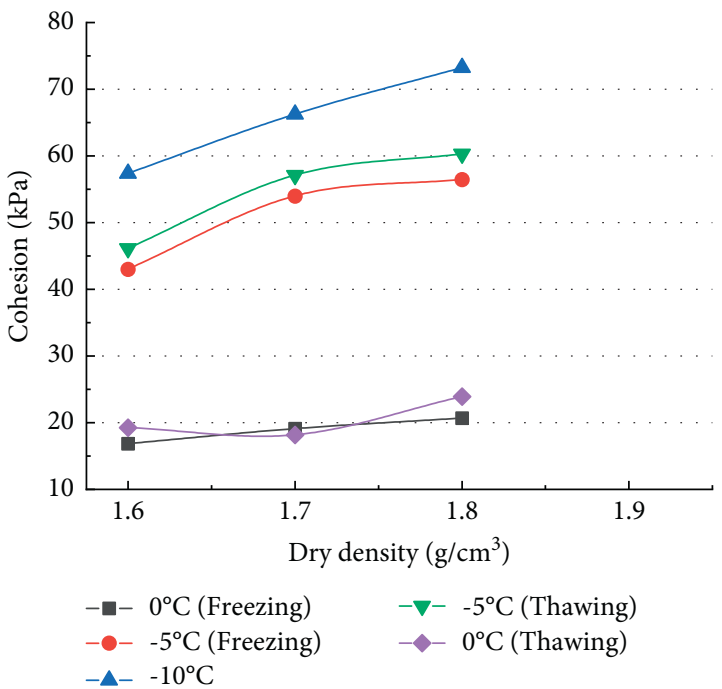

(b)

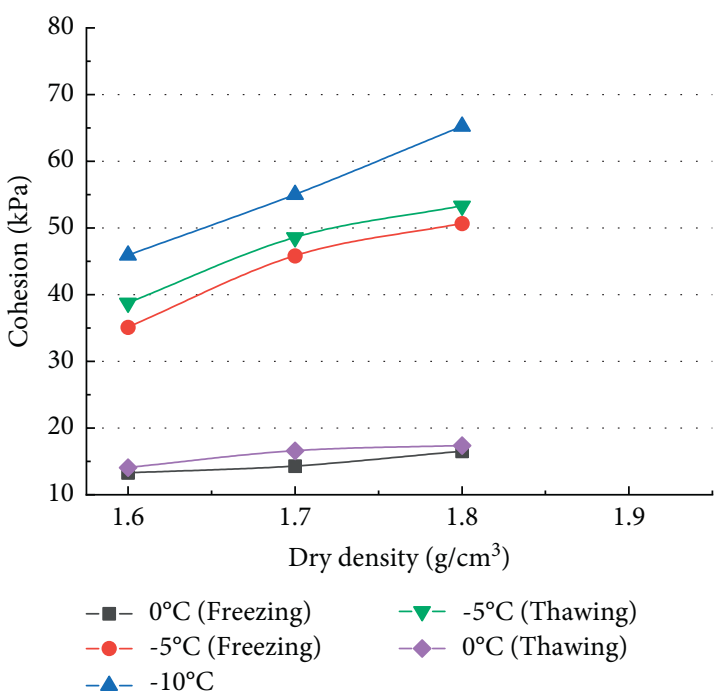

(d)

FIGURE 10: Relationship curve between cohesion $c$ of sample group and dry density under freeze-thaw action. (a) Initial moisture content 12\%. (b) Initial moisture content 15\%. (c) Initial moisture content 18\%. (d) Initial moisture content $20 \%$.

significantly greater than the $0^{\circ} \mathrm{C}$ curve. While temperature varies from $-5^{\circ} \mathrm{C}$ to $-10^{\circ} \mathrm{C}$, the back-end growth rate catches up with the front-end, the curve begins to show linear growth again, and the overall slope of the curve is greater than the $0^{\circ} \mathrm{C}$ curve.

The results above show the following. Firstly, the increase in sample density has a significant effect on the increase of cohesion at each temperature condition. Secondly, the cohesion growth rate corresponding to the dry density increases gradually as the temperature decreases, and the growth rate of cohesion of low dry density samples is more easily influenced by temperature.

Similarly, for the internal friction angle, taking Figure 11(a) as an example, the internal friction angle curves grow linearly and parallel to each other at each temperature. Although the slopes of the other curves do not all increase linearly, the slope of each temperature curve at the same dry density remains unchanged, indicating that the freezing temperature does not affect the growth rate of the internal friction angle, which is different from the conclusion that the 


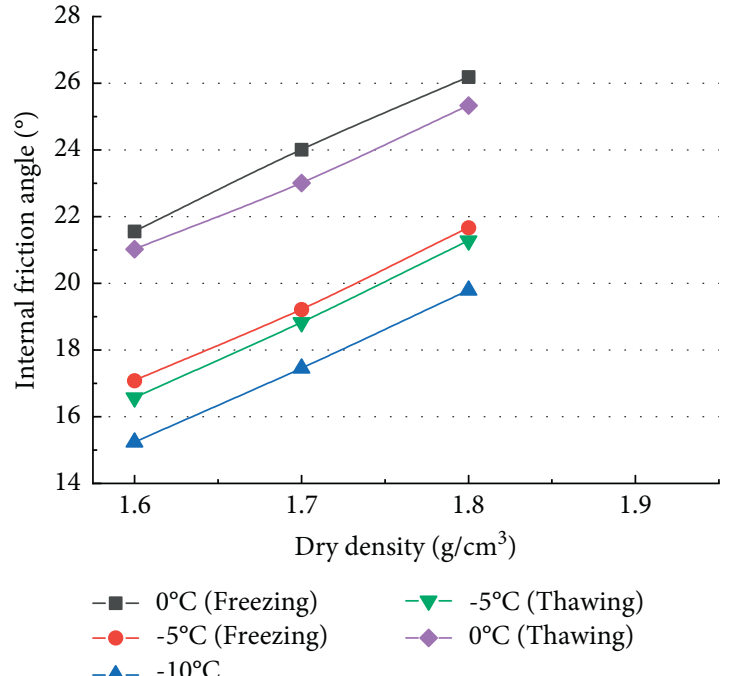

(a)

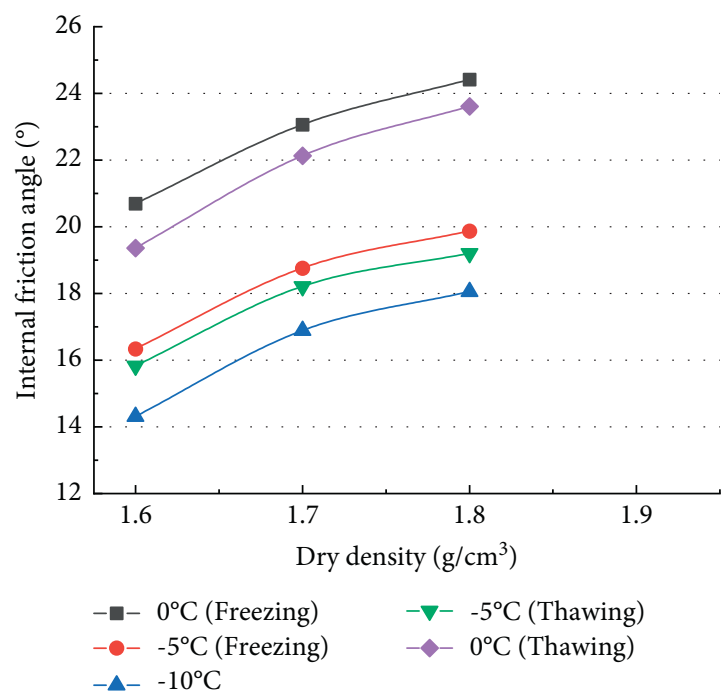

(c)

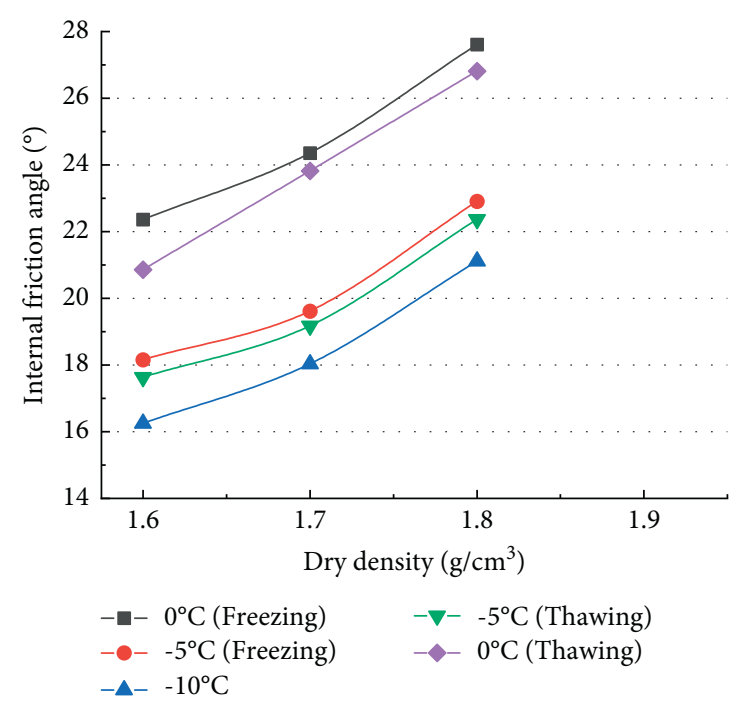

(b)

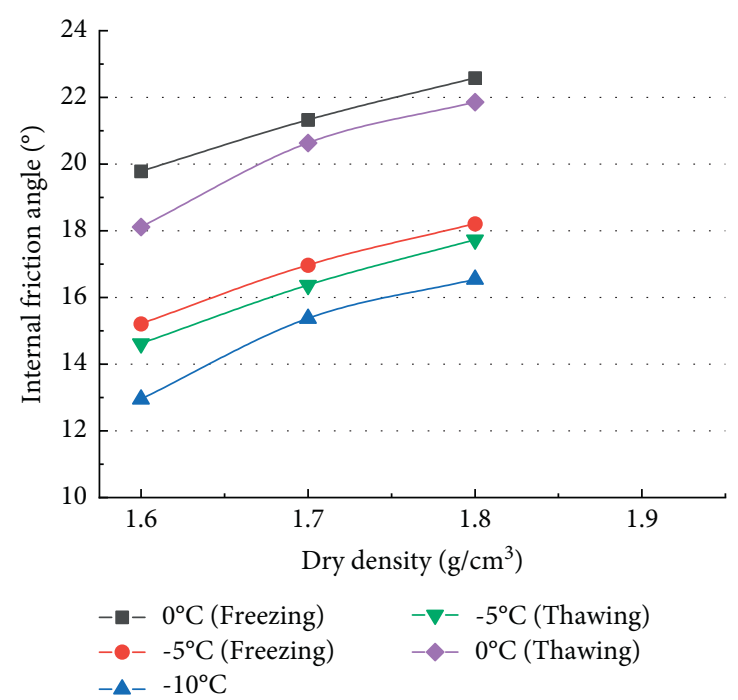

(d)

Figure 11: Relationship curve between internal friction angle $\varphi$ and dry density of sample group under freeze-thaw action. (a) Initial moisture content $12 \%$. (b) Initial moisture content 15\%. (c) Initial moisture content $18 \%$. (d) Initial moisture content $20 \%$.

cohesion of the frozen soil with low dry density is more susceptible to temperature.

\section{Conclusion}

In this work, the direct shear test of different dry density and moisture content samples at different temperatures during the freezing and thawing process of the frozen soil of the Qinghai-Tibet Railway between Tanggula South and Anduo section was carried out, and the influence of each test factor on the mechanical properties of the frozen soil during this process was analyzed, which produced the following main conclusions:

(1) The cohesive force and internal friction angle are unchanged during the freezing and thawing process from 0 to $2^{\circ} \mathrm{C}$. As the temperature decreases below $0^{\circ} \mathrm{C}$ and continues to decrease, the cohesive force of each sample shows a sharp increase (241\% 295\%). In contrast, the internal friction angle decreases slightly $(23.5 \% \sim 34.5 \%)$. The cohesive force obtained during the thawing process of the sample at the same shear temperature point is higher than that during the freezing process, whereas the internal friction angle shows an opposite property. When freezing and thawing are completed, the cohesion rises sightly $(0.5 \% \sim 21.1 \%)$ and the internal friction angle shows a slight decrease trend (2.1\% 8.4\%).

(2) With the decrease in temperature and increase of cohesion, the corresponding slope within the temperature range can be divided into three stages due to the combined effect of pressure-thawing and icewater phase change. In the range of $0 \sim-2^{\circ} \mathrm{C}$, a large 
number of ice crystals exert their strength and cement the soil particles owing to the intense ice-water phase change, and the cohesive force increases rapidly. In the range of $-2 \sim-8^{\circ} \mathrm{C}$, for the reason that the water content is reduced and the pressurethawing effect inhibits the generation of ice crystals, the growth rate slows down. In the range of $-8 \sim-10^{\circ} \mathrm{C}$, as the pressure-thawing effect disappears with the decrease of temperature, the inhibition vanishes and the cohesion begins to increase rapidly for the second time, and the decline rate of the internal friction angle also shows similar patterns.

(3) The samples' cohesive force and internal friction angle show a climbing trend and then decline with the rising of the initial moisture content, the critical point of which is located at or near the optimal moisture content of $15 \%$. In this case, both the cohesion and the internal friction angle obtain peak values.

(4) Both the cohesion and the internal friction angle increase with the increase of dry density. And the cohesion growth rate corresponding to the dry density will gradually increase as the temperature decreases. Moreover, the growth rate of cohesion of low dry density samples is more susceptible to temperature, while the internal friction angle growth rate is exempt from such influence.

\section{Data Availability}

The data used to support the findings of this study are included within the article.

\section{Conflicts of Interest}

The authors declare no conflicts of interest.

\section{Acknowledgments}

The authors gratefully acknowledge the support provided by the National Natural Science Foundation of China (nos. 51878571 and U2034205) and the Fundamental Research Funds for the Central Universities, CHD (30010220516).

\section{References}

[1] X. Xu and M. Qiu, Advanced Soil Mechanics [M], Harbin Institute of Technology Press, Harbin, China, 2008.

[2] S. E. Chadburn, E. J. Burke, P. M. Cox, P. Friedlingstein, G. Hugelius, and S. Westermann, "An observation-based constraint on permafrost loss as a function of global warming," Nature Climate Change, vol. 7, no. 5, pp. 340-344, 2017.

[3] M. James, A. G. Lewkowicz, S. L. Smith, and C. M. Miceli, "Multi-decadal degradation and persistence of perma-frost in the Alaska highway corridor, northwest Canada[J]," Environmental Research Letters, vol. 8, no. 4, Article ID 045013, 2013.

[4] M. Johansson, J. Åkerman, F. Keuper, T. R. Christensen, H. Lantuit, and T. V. Callaghan, "Past and present permafrost temperatures in the a area: rb," Ambio, vol. 40, no. 6, pp. 558-565, 2011.

[5] T. V. Callaghan, C. Jonasson, T. Thierfelder et al., "Ecosystem change and stability over multiple decades in the Swedish subarctic: complex processes and multiple drivers[J]," Philosophical Transactions of the Royal Society B: Biological Sciences, vol. 368, 2013.

[6] G. Cheng and H. Jin, "Groundwater and its changes in permafrost regions of the Tibetan Plateau [J]," Hydrogeological engineering geology, vol. 40, no. 01, pp. 1-11, 2013.

[7] Y. Feng, Quantitative Analysis of Permafrost Changes in the Tibetan Plateau and its Ecological and Hydrological Significance [D], China University of Geosciences, Beijing), China, 2015.

[8] S. Wei, Mechanical Properties and Deformation Prediction of Subgrade Filling under Freeze-Thaw Action [D], Xi'an University of Science and Technology, Xi'an, China, 2020.

[9] Di Zheng, Study on Typical Geological Disasters in Permafrost Regions in the Hinterland of the Qinghai-Tibet Plateau [D], China University of Geosciences, Beijing), China, 2009.

[10] O. J. Ferrians and R. Kachadoorian, Permafrost and Related Engineering Problems in Alaska[R], USGS, Reston, Virginia, 1969.

[11] S. Wang, F. Niu, J. Chen, and Y. Dong, "Permafrost research in China related to express highway construction," Permafrost and Periglacial Processes, vol. 31, no. 3, pp. 406-416, 2020.

[12] S. Yao, L. Cai, and M. Hu Lin, "Discussion on geological disaster protection technology of pipelines in alpine permafrost regions [J]," Petroleum and chemical equipment, vol. 23, no. 5, pp. 90-92, 2020.

[13] X. Dong and Z. Dang, "Briefly discussed the matters needing attention in the construction of catenary foundation in permafrost regions of the Gra section of Qinghai-Tibet Railway [J]," Sichuan Cement, no. 07, pp. 250-251, 2020.

[14] J. Wu, S. Yu, Q. Wu, and Z. Wen, "The process and mode of permafrost degradation in the Qinghai-Tibet Plateau [J]," Chinese Science (D: Geoscience), vol. 39, no. 11, pp. 1570-1578, 2009.

[15] S. Li, Z. Nan, and L. Zhao, "Effect of freeze-thaw on energy exchange between system and environment," Glacier permafrost, vol. 24, no. 2, pp. 109-115, 2002.

[16] S. Wang, Research on Highway Subgrade Stability and Prediction Technology in Plateau Permafrost Region [D], Southeast University, Nanjing, China, 2005.

[17] R. W. Van Klaveren, Hydraulic Erosion Resistance of Thawing soil[D], Department of Agricultural Engineering, Washington State University, Washington, USA, 1987.

[18] B. D. Alkire and J. M. Morrison, "Change in soil structure due to freeze-thaw and repeated loading[J]," Transportation Research Record, vol. 18, no. 9, pp. 15-21, 1983.

[19] C. Song, J. Qi, and F. Liu, "The effect of freeze-thaw on the mechanical properties of Lanzhou loess [J]," Geotechnical mechanics, no. 04, pp. 1077-1080+1086, 2008.

[20] X. Yao, J. Qi, and C. Song, "Effect of freeze-thaw action on engineering properties of Qinghai-Tibet clay [J]," Glacier permafrost, no. 01, pp. 165-169, 2008.

[21] Li-X. Zhang, X.-Z. Xu, Z.-X. Zhang, and Y.-S. Deng, "Experimental study of the relationship between the unfrozen water content of frozen soil and pressure," Journal of Glaciology and Geocryology, vol. 2, pp. 28-31, 1998.

[22] Z. Zhou, S. Zhong, and L. Han, "Test on the influence of freeze-thaw cycles on road performance of loess [J]," Journal of Chang'an University (Natural Science Edition), vol. 33, no. 4, pp. 1-6, 2013. 
[23] A. Hotineanu, M. Bouasker, A. Aldaood, and M. Al-Mukhtar, "Effect of freeze-thaw cycling on the mechanical properties of lime-stabilized expansive clays," Cold Regions Science and Technology, vol. 119, no. 11, pp. 151-157, 2015.

[24] D. Wang, W. Ma, X. Chang, Z. Sun, W. Feng, and J. Zhang, "The effect of freeze-thaw cycles on the physical and mechanical properties of Qinghai-Tibet clay [J]," Rock mechanics and engineering, no. 23, pp. 4313-4319, 2005.

[25] T. Hu, J. Liu, and Q. Wang, "etc. Experimental study on undrained shear properties of silty clay under freeze-thaw cycles [J]," Journal of Central South University, vol. 49, no. 6, pp. 1481-1490, 2018.

[26] He Wu, Ge Qi, and J. Bo Tian, "Study on the shear strength parameters under different freezing and thawing cycles of soil slope in China[J]," Applied Mechanics and Materials, vol. 454, p. 2818, 2014

[27] Y. Mu, T. Chen, G. Chen, F. Niu, J. Luo, and G. Bi, "Experimental study on the effect of freeze-thaw cycles on shear strength of clay coarse grained soil [J]," Journal of Disaster Prevention and Reduction Engineering, vol. 39, no. 03, pp. 375-386, 2019. 